\title{
Medical Students in Developing Countries
}

\author{
Jessica Merlin, MD, MBA?', Gail Morrison, MD², Stephen Gluckman, MD', Gregg Lipschik, MD ${ }^{3,4}$, \\ Darren R. Linkin, MD, MCSE ${ }^{1,5}$, Sarah Lyon, $M D^{4}$, Elizabeth $O^{\prime}$ Grady, $B S^{2}$, Heather Calvert, $B A^{6}$, \\ and Harvey Friedman, $M D^{1,6}$
}

\begin{abstract}
${ }^{1}$ Hospital of the University of Pennsylvania, Division of Infectious Diseases, Philadelphia, PA, USA; '2University of Pennsylvania School of Medicine, Philadelphia, PA, USA; ${ }^{3}$ Penn Medicine Clinical Simulation Center, Philadelphia, PA, USA; ${ }^{4}$ Division of Pulmonary Critical Care, Hospital of the University of Pennsylvania, Philadelphia, PA, USA; ${ }^{5}$ Center for Clinical Epidemiology and Biostatistics, Philadelphia, PA, USA; ${ }^{6}$ Botswana-UPenn Partnership, Philadelphia, PA, USA.
\end{abstract}

To the Editor:-We appreciate Dr. Cooke's thoughtful comments about our study of blood and body fluid exposures among US medical students in Botswana.

We are sensitive to the perils of "medical tourism," and have designed our program to avoid it. Our medical students are members of medical teams under the supervision of local physicians. In turn, Penn specialists who live and work full time in Botswana are assigned to supervise the ward work of interns and residents hired by the Ministry of Health and the University of Botswana School of Medicine.

Dr. Cooke expressed concern regarding the availability of protective eye gear to Penn trainees but not local doctors. When a local provider performs a procedure, our students offer them their goggles. In most cases, the offer is declined. Importantly, we think it is unwise for a visiting institution like Penn to impose its safety standards on the host institution. However, we think it is critical that Penn provides the level of safety it deems appropriate for its

Published online May 20, 2011 trainees. We believe it is the decision of the governing body, in this case the Ministry of Health, to make recommendations concerning protection of the health care work force in Botswana.

Concerning the issue of post-exposure prophylaxis, the Botswana Ministry of Health provides HIV post-exposure prophylaxis to health care workers. In our partnership with the Government of Botswana, we view our role as working with our fellow health care providers to identify and prioritize issues of concern, and to support them as they try to make changes that they think are appropriate locally.

Jessica Merlin, MD, MBA, Hospital of the University of Pennsylvania, Division of Infectious Diseases, Philadelphia, PA, USA (e-mail: jessicasarahmerlin@gmail.com).

J Gen Intern Med 26(8):833

DOI: $10.1007 / \mathrm{s} 11606-011-1744-3$

(c) Society of General Internal Medicine 2011 